\title{
Resolução de Conflitos Interpessoais: Interações entre Cognição e Afetividade na Cultura
}

\author{
Maria Isabel da Silva Leme ${ }^{12}$ \\ Universidade de São Paulo
}

\begin{abstract}
Resumo
Foram realizados 2 estudos para esclarecer aspectos envolvidos na violência interpessoal e algumas inter-relações entre cognição e afetividade no funcionamento psicológico. No primeiro estudo, a Escala Children's Action Tendency Scale (CATS) foi aplicada em uma amostra de 779 alunos de $2^{\mathrm{a}}$ a $7^{\mathrm{a}}$ série. As tendências de resolução de conflito encontradas, assertividade, submissão e agressividade coincidiram com as encontradas por Deluty na amostra americana. Porém, foram encontradas diferenças significativas nas médias de submissão e assertividade entre as duas amostras. No segundo estudo foi usada a versão abreviada com uma amostra de 320 alunos de $5^{a}$ à $7^{\mathrm{a}}$ série. Foram encontradas diferenças entre os 2 estudos nas tendências predominantes de resolução de conflitos, pois no segundo, submissão e agressividade sobrepujaram a assertividade, que ficou em último lugar. Tais resultados são discutidos como fruto de inter-relações entre contexto de pesquisa, idade, gênero e cultura.

Palavras-chave: Resolução de conflito interpessoal; cognição; afetividade; cultura.
\end{abstract}

Interpersonal Conflict Solving: Interactions among Cognition and Emotion in Culture

\begin{abstract}
Two studies were conducted in order to assess some issues involved into interpersonal violence, and also to achieve more understanding about the cognitive and affective interrelationships on psychological functioning. In Study 1, the complete version of The Children's Action Tendency Scale (CATS) was used to assess conflict resolution tendencies in a sample of $7792^{\text {nd }}$ to $7^{\text {th }}$ grade students. The main tendencies of conflict resolution, assertiveness, submissiveness and aggression found among Brazilian students were the same found for the American sample, but some significant differences regarding submissiveness and assertiveness were also found. In Study 2 , the short version of the scale was administered to a sample of $3205^{\text {th }}$ to $7^{\text {th }}$ graders, in which the main tendencies identified in this study were submissiveness, aggressiveness and assertiveness, as well as a mixture of the first two tendencies. These results are discussed as being influenced by interrelations of research context, age, sex, and culture.

Keywords: Interpersonal conflict resolution; cognition;emotion; culture.
\end{abstract}

Presenciamos atualmente, com preocupação, o crescimento alarmante da violência, que, segundo a Organização Mundial de Saúde, ocasionou 1,7 milhões de óbitos em 2000(Yunes, 2002). Este dado torna-se ainda mais preocupante quando se verifica, segundo a mesma fonte, que as principais vítimas e perpetradores da violência interpessoal são adolescentes e jovens adultos. Tal preocupação nos motivou a realizar a presente pesquisa, que teve por objetivo geral contribuir para a compreensão de alguns aspectos envolvidos neste fenômeno. Selecionouse, assim, como variáveis de estudo, as tendências de resolução de problemas interpessoais em crianças e adolescentes, pois, como já mostrado nos dados da OMS, o conflito interpessoal representa fator de risco para estas faixas etárias. Além disso, a resolução do conflito interpessoal é uma situação que mobiliza conjuntamente recursos cognitivos e afetivos, facilitando a compreensão de como

\footnotetext{
${ }^{1}$ Endereço para correspondência: Instituto de Psicologia, USP, Avenida Prof. Mello Moraes, 1721, 005508 900, São Paulo, SP. Fone: (11) 3091 4355. E-mail: belleme@usp.br

${ }^{2}$ A autora agradece à Profa ${ }^{a}$ Dr ${ }^{2}$. Maria Alice Vanzolini da Silva Leme e ao Prof. Dr. Yves de La Taille pela leitura e categorização das respostas. Apoio Institucional: Bolsa de Iniciação Científica/ CNPq
}

estes aspectos interagem na regulação da conduta. Os conflitos interpessoais, aqui entendidos como situações de interação social de confronto, desacordo, frustração, etc., e que são, portanto, desencadeadoras de afeto negativo, podem ser resolvidos de maneira violenta ou pacífica, dependendo, justamente, dos recursos cognitivos e afetivos dos envolvidos, e dos contextos sociais em que ocorrem. Neste sentido, a resolução de problemas, como o conflito interpessoal, fornece informações importantes para o esclarecimento desta mobilização conjunta de afeto e conhecimento, e seu papel no funcionamento psicológico na infância e adolescência, em um dado contexto cultural. É interessante observar ainda que cognição e afetividade têm sido pouco investigadas em uma perspectiva de funcionamento integrado até recentemente pela Psicologia (Sastre \& Moreno, 2002).

A pesquisa a ser relatada compreende dois estudos, utilizando duas versões de um mesmo instrumento, desenvolvido e cedido por Deluty (1979), que avalia, concomitante e comparativamente, três tipos de tendências de resolução de conflitos interpessoais, agressivas, submissas e assertivas, por meio de descrição de situações sociais como provocação, perda, frustração, e outras. É importante salientar que não encontramos instrumentos em nosso meio que 
avaliassem desta forma as várias tendências de resolução, pacíficas ou violentas, de problemas do tipo conflitos interpessoais, razão pela qual utilizamos o desenvolvido, validado e cedido por Deluty em sua tese de doutorado nos Estados Unidos. O instrumento mostrou-se válido, também, com uma população de crianças e adolescentes americanas de descendência latina (Briggs, Tovar \& Corcoran, 1996), outra razão pela qual selecionou-se o instrumento para pesquisar como crianças e adolescentes resolvem este tipo de problema em nosso meio.

No primeiro estudo, investigamos como uma amostra de alunos de primeiro grau de escolas públicas e privadas respondia à escala de conflito interpessoal contendo alternativas fechadas, The Children's Action Tendency Scale (CATS), conforme desenvolvida inicialmente por Deluty (1979). Dados os resultados obtidos nesta primeira pesquisa, em que constatamos alguns aspectos que nos chamaram a atenção, como diferenças significativas na comparação com a amostra americana estudada por Deluty, e no seio da própria amostra brasileira, realizamos um segundo estudo, envolvendo basicamente as mesmas descrições de situações, porém sem as alternativas, como um questionário aberto (Deluty, 1981).

A introdução teórica, a seguir, trata do que a literatura da área já elucidou sobre a resolução de conflitos interpessoais, que nos auxiliaram tanto no levantamento de hipóteses como na interpretação dos resultados. Encontram-se nesta revisão as principais tendências de resolução de conflitos interpessoais identificadas, e que são avaliadas pela escala usada, assim como os fatores que contribuem para a predominância de uma sobre outra. A seguir, são descritos os dois estudos, os resultados alcançados e as conclusões favorecidas pela comparação dos mesmos.

\section{A Agressividade como Tendência de Resolução de Conflitos Interpessoais}

Como será possível constatar a seguir, a agressividade é a tendência de resolução de conflitos interpessoais mais estudada na literatura, provavelmente por envolver maior risco para os envolvidos nos possíveis confrontos que enseja. É, ainda, a que mais apresenta dificuldades como objeto de investigação porque, como será analisado a seguir, o comportamento dela resultante, a agressão, é uma conduta que, além de episódica, não é facilmente definível, assumindo diferentes formas de manifestação, cuja evolução é também variável, e também, porque está sujeita à influência de variáveis, tanto biológicas como sociais.

No que diz respeito ao problema da definição, verificase que uma ampla gama de comportamentos são considerados agressivos, variando do exemplo extremo, ataque físico a formas mais veladas, como a maledicência. O que pode ser identificado de comum nestes comportamentos é a intenção de causar prejuízo ao outro, aliada à expectativa de que tal objetivo será atingido (Edmunds \& Kendrick, 1980; Geen, 1990; Loeber \& Stouthamer-Loeber, 1998). Entretanto, também a atribuição de intencionalidade pode apresentar problemas como critério definidor, por estar sujeita à contaminação do juízo moral do observador (Tremblay, 2000). A frustração intensa, por exemplo, pode desencadear comportamento muito violento que, aparentemente, não é motivado pelo desejo de causar dano. Outro aspecto que deve ser lembrado, ligado, diretamente, à questão da intencionalidade envolvida na agressão, é que, muitas vezes, um ato não é julgado agressivo, pois não provoca dano, como, por exemplo, quando uma criança pequena, cuja força ainda é insignificante, joga um objeto em alguém.

\section{Variáveis desencadeadoras}

Com relação às variáveis que influem sobre o surgimento e manutenção da agressão, verificamos que, apesar das indicações da existência de um componente biológico, de função adaptativa, podem ser apontados muitos outros fatores que intervêm sobre o processo: variáveis pessoais como personalidade, experiências anteriores, expectativas sócioculturais, que formam o potencial individual de agressão, dirigindo o comportamento. Dentre estas últimas, variáveis como cultura familiar e exposição à mídia violenta também influem, no sentido de seu incremento ou diminuição, por meio da aprendizagem (Geen, 1990). Por outro lado, intervêm também no processo variáveis situacionais, como frustração, ataque, conflito, violações da norma e elementos ambientais estressantes, como calor, ruído, que influem no sentido de ativar o indivíduo, predispondo-o para o comportamento agressivo. É importante ressaltar, porém, que este comportamento é desencadeado após um processo de avaliação complexo, no qual interagem as variáveis pessoais e situacionais citadas, que aumentam ou diminuem o nível de ativação necessário para impulsionar a conduta agressiva.

Aprofundando um pouco o papel da aprendizagem, pelo grande interesse que tem para a Psicologia, no sentido da prevenção, verifica-se que a exposição à violência tem como conseqüência o aumento da probabilidade de que sejam mantidos ativos na memória scripts, também violentos, redundando, possivelmente, em uma maior ativação, que pode influir sobre o processo de avaliação de situações complexas, novas ou ambíguas (Geen, 1990). Detalhando um pouco mais este processo, todas as emoções passam por um processo de avaliação cognitiva, bastante complexo e universal, das várias dimensões envolvidas na situação desencadeadora. Tal avaliação inclui valência, isto é, se o evento eliciador é positivo ou negativo, análise da agência causadora da emoção, intenção da mesma, adequação às 
normas sociais do evento eliciador e da própria emoção resultante, grau de incerteza sobre as conseqüências envolvidas na situação, grau de controle, e, finalmente, esforço a ser despendido no lidar com a situação. É importante salientar aqui alguns aspectos. A avaliação é dinâmica, ou seja, à medida que transcorre o tempo em que novas informações são incorporadas, as dimensões são reavaliadas, reordenadas, resultando, às vezes, em mudança na própria emoção experimentada. Embora estas dimensões sejam provavelmente universais, na medida em que fazem parte de situações comuns à vida de qualquer indivíduo, em qualquer sociedade, como ataque, perda, surpresa etc., elas, também variam, no sentido em que cada cultura estabelece normas sobre o que consiste novidade, ameaça, etc. Um terceiro aspecto importante diz respeito à incorporação gradual de tais normas no sistema de crenças e valores do indivíduo, à medida em que se processa a sua socialização em uma dada cultura (Ellsworth, 1994). A tendência do sistema cognitivo é a organização, abstração e retenção destas experiências recorrentes em esquemas de situações típicas, os chamados scripts, muitas vezes como instanciação da própria norma (Sternberg, 1996). É neste sentido, portanto, que a exposição à violência representa risco, principalmente no início da vida: os esquemas de interação social que estariam se formando e organizando nesta fase, para a solução de problemas do tipo conflito interpessoal, teriam maior probabilidade de ser de natureza mais violenta também, ocasionado distorções na interpretação de intenções, estreitando o espectro de opções de resolução, etc.

\section{Evolução da agressividade}

Relacionada a este último aspecto, a formação de esquemas, normas, crenças e valores que intervêm no desencadeamento da conduta, encontra-se a questão da estabilidade do comportamento agressivo, se é interrompido, ou se evolui para formas cada vez mais graves de comportamento. Esta questão também apresenta dificuldades porque, como já mencionado, a agressão é um comportamento episódico e, além disso, pode manifestar-se posteriormente de forma mais privada, como violência doméstica contra cônjuges e filhos (Loeber \& StouthamerLoeber, 1998). E ainda, uma proporção importante de indivíduos agressivos revela-se depois do período da préescola, com evolução gradual, que se estende por muitos anos, sendo o período mais violento por volta dos 10 anos. Ao que tudo indica, há várias fases de surgimento: precoce, nos anos pré-escolares, e mais retardado, na passagem da infância para a adolescência, sendo provável que nas primeiras encontrem-se meninos com desordens de atenção, que acabam se associando a funcionamento cognitivo e acadêmico pobre, comportamento negativista, que evolui progressivamente para comportamento agressivo. Os indivíduos que se revelam mais tardiamente, aparentemente, não apresentam desordens atencionais, supondo-se que este grupo seja composto, também, por meninos, que manifestam precocemente comportamento negativista, que evolui na adolescência para agressão explícita, furtiva, ou ambas. Neste período, a agressão é tão comum, que cabe o alerta de alguns autores como Borum (2000), de que índices mais elevados de agressão tornem-se normativos. Há ainda uma minoria que emerge na vida adulta, por volta dos 30 anos, composta por indivíduos de ambos os sexos, que anteriormente mostravam-se super controlados e submissos.

Felizmente, como muitas pesquisas constatam, a interrupção da agressão é bastante generalizada, principalmente do tipo físico, da infância para a vida adulta. Porém, a probabilidade de interrupção é inversamente proporcional à gravidade das transgressões cometidas pelo indivíduo, provavelmente porque as conseqüências ao seu comportamento vão limitando, cada vez mais, as oportunidades de estudo e, posteriormente, de trabalho. Em outras palavras, é bem menos provável que indivíduos altamente agressivos desistam da reação agressiva do que indivíduos moderadamente agressivos, em função de sanções sofridas, que acabam por limitar sua formação educacional. Outro risco que correm as crianças agressivas é o isolamento social. Este tipo de comportamento desperta rejeição por parte de outras crianças, gerando um círculo vicioso, na medida em que a experiência do isolamento provoca sentimentos negativos como raiva, que aumentam a probabilidade de ocorrência do comportamento agressivo (Morais, Otta \& Scala, 2001).

Um outro aspecto importante a ser mencionado, relacionado às questões de definição, do período de surgimento e da evolução, diz respeito à existência de mais de uma trajetória de comportamento agressivo. Tal controvérsia, de fato, repousa sobre uma questão anterior, da necessidade de se distinguir entre diferentes formas deste tipo de comportamento, isto é, comportamento explícito que envolve confronto direto com o outro, e furtivo, que não envolve confronto, como fraude ou roubo. Embora sejam, realmente, formas distintas de conduta, nas avaliações das pessoas próximas, as duas formas não são exclusivas, havendo casos de indivíduos que apresentam os dois tipos de comportamentos. O modelo de uma só trajetória supõe que o comportamento agressivo inicia com desobediência, evolui para ataques de mau gênio, e daí em diante, para formas mais sérias como luta e roubo. Não explica a especialização em uma forma de atos violentos. Já um dos modelos de mais de uma trajetória (Loeber \& StouthamerLoeber, 1998) propõe que estas poderiam ser concebidas como as vertentes de uma pirâmide, na base da qual estão 
comportamentos menos violentos, do tipo conflito com autoridade, teimosia, desobediência, cometidos por uma grande proporção de crianças. Na parte intermediária desta pirâmide, pela diminuição no número de indivíduos envolvidos, estão duas trajetórias: uma explícita que envolve provocações, seguidas de brigas físicas, e deste ponto em diante, para delitos muito graves como estupro, ataque, etc. $\mathrm{Na}$ vertente complementar, da agressão furtiva, estão envolvidos comportamentos como furto em lojas, vandalismo e outras formas de desrespeito à propriedade, que evoluem para formas mais graves de delito, como fraude, roubo, etc.

A seqüência destes comportamentos é outra fonte de controvérsia relacionada, estreitamente, à questão da existência de mais de uma trajetória e mais de um tipo de agressão. Algumas seqüências foram identificadas e são importantes no que tange à prevenção: de modo geral, o processo desenvolve-se de modo ordenado, progredindo das transgressões menos graves, como desobediência, para outras como roubo e, daí, para atos violentos explícitos. Muitos jovens não ultrapassam os primeiros estágios de agressão furtiva, o que ainda é pouco explicado pelas pesquisas.

\section{Aspectos Cognitivos e Afetivos Envolvidos na Agressão}

Outra polêmica entre os pesquisadores e de interesse para a presente pesquisa é se as diferentes formas de agressão, furtiva e explícita, partilham as mesmas causas. No que tange à afetividade, verifica-se o envolvimento de emoções diferentes: a raiva geralmente acompanha a explícita, enquanto a furtiva é acompanhada por afetos mais neutros, exceto pelo dano à propriedade alheia, que é voltado para prejudicar o outro (Loeber \& Stouthamer-Loeber, 1998). Com relação aos aspectos cognitivos, observam-se diferenças marcantes: na explícita é verificada dificuldade em encontrar soluções não agressivas para conflitos interpessoais e um viés nas inferências sobre as intenções alheias (Astor, 1994; Deluty, 1995; Loeber \& Hay, 1997). Os aspectos cognitivos dos perpetradores da agressão furtiva são menos conhecidos, mas supõe-se que as dificuldades mencionadas não se aplicam. Pelo contrário, este tipo de agressão exige habilidades cognitivas mais sofisticadas, como planejamento, preocupação com consumo, propriedade e mentira para escapar à punição (Loeber \& Stouthamer-Loeber, 1998). Alguns estudos localizaram causas na família para este tipo de transgressão: castigos físicos muito severos, de acordo com alguns estudos revistos, induzem a um comportamento furtivo, mais típico da agressão como roubo etc., assim como ausência de explicitação de valores como honestidade e respeito à propriedade alheia por parte dos pais no processo de socialização. Por outro lado, punições sofridas na infância, tão severas que caracterizam violência doméstica, aumentam a probabilidade das vítimas tornarem-se futuros agressores de seus familiares (Azevedo \& Guerra, 1995). Entretanto, Loeber e Hay (1997) discutem que o estilo de punição, ou mesmo de relação familiar, não pode ser considerado determinístico: crianças de famílias problemáticas aprendem a compensar as circunstâncias familiares adversas. Vale salientar que resultados apontando na mesma direção foram encontrados em nosso meio (Cecconello \& Koller, 2000).

A posição familiar também é importante, pois crianças com irmãos mais velhos são mais desenvolvidos na habilidade cognitiva social, a chamada teoria da mente, do que filhos únicos, e inferem melhor as intenções alheias. Outro fator a ser destacado é o gênero, nem sempre considerado por todos pesquisadores como determinante. Talvez, mais importante que esta questão, seja a suposição decorrente de que meninos e meninas seguem a mesma trajetória. Ao que tudo indica, fatores ligados à socialização têm um peso não desprezível, pois não se constatou diferença significativa quanto a este aspecto na primeira infância, o que se aplica, também, a outras emoções (Ellsworth, 1994). Já no período pré-escolar, começam a se manifestar, pois os meninos começam a mostrar maior tendência do que meninas a agredir fisicamente (Otta \& Sousa, 1999) em determinados contextos (Magalhães \& Otta, 1995). Além disso, meninas, quando transgridem neste aspecto, iniciam mais tarde, geralmente na adolescência.

\section{Atitudes e valores}

Um aspecto bastante relacionado ao que foi discutido anteriormente diz respeito ao peso das atitudes dos indivíduos sobre a probabilidade de agredir ou não (Loeber \& Hay, 1997). Os resultados a este respeito são conflitantes em relação à associação da agressão a atitudes positivas frente à violência. Ao que tudo indica, a associação entre atitudes favoráveis à violência e agressão aumenta com a idade, assim como a estabilidade, e também, a previsibilidade mútua, da atitude prever comportamento, e este último prever a primeira. Com relação ao aspecto da transferência do comportamento, verifica-se variação de acordo com o contexto: nem todos que agridem em casa fazem o mesmo na escola, e viceversa. É possível, porém, generalizar de um contexto para outro, sendo mais provável de casa para a escola do que o inverso (Loeber \& Hay, 1997). Quanto à interveniência destes fatores sobre a interrupção do comportamento agressivo, e também, sobre a sua estimulação, verifica-se que esta é uma área negligenciada pelas pesquisas, que têm se concentrado mais na delinqüência (Loeber \& Hay, 1997). As principais causas apontadas para a desistência são a construção de ligações fortes com instituições adultas como família, trabalho e comunidade. Ao que tudo indica, a desistência ocorre na adolescência e está diretamente relacionada à gravidade dos atos cometidos, sendo ainda, função da percepção do 
perpetrador das conseqüências do seu ato e da probabilidade de ocorrência de sanção social para os mesmos. Esta percepção é fruto de uma mudança do poder das sanções externas para a transgressão, como, por exemplo, disciplina dos pais, para uma regulação interna do comportamento. $\ddot{\mathrm{E}}$ muito provável que a habilidade de regular emoções negativas, como raiva e impaciência, desempenhe um papel importante na interrupção da agressão e da violência. A desistência é, possivelmente, resultado da adoção de valores e padrões de conduta não violentos. Tal mudança precisa, todavia, ser mais investigada, principalmente entre jovens do sexo masculino, para verificar se adotaram mesmo valores contrários à violência, ou se simplesmente, passaram a praticar violência doméstica contra a esposa e os filhos para uma inserção social no mundo do trabalho e da comunidade. Concluindo, os fatores protetores e de risco foram bastante investigados, mas poucos resultados sólidos encontrados, exceto que as meninas são mais vulneráveis a problemas familiares graves. Uma observação interessante relacionada a este aspecto (Loeber \& Hay, 1997) é sobre a necessidade de mais pesquisas que focalizem os fatores protetores, principalmente, se aqueles que resguardam as meninas, de modo geral menos transgressoras, protegeriam também os meninos. A este respeito, vale lembrar uma certa cautela: Cecconello e Koller (2000) alertam para resultados da literatura sobre Psicopatologia do Desenvolvimento, que relatam que meninos tendem a exteriorizar os sintomas de má adaptação pela agressividade ou adição a drogas, enquanto as meninas tendem a internalizá-los pela depressão e ansiedade.

Finalmente, um resultado importante relacionado ao aspecto anterior: a agressividade responde bem a programas de intervenção, que infelizmente, são realizados mais freqüentemente na idade escolar, quando a agressão já pode ter surgido e se instalado, sem que a criança tenha aprendido a regulação da mesma (Tremblay, 2000).

Resumindo o que foi examinado acima: a agressão é um comportamento que apresenta dificuldades para ser investigado em função: 1) da grande amplitude de condutas consideradas agressivas manifestas e encobertas; 2) da dependência de critérios subjetivos, como os valores de quem observa o comportamento e emite um juízo; 3) é causado por vários fatores, cujo peso varia de acordo com a idade e gênero dos envolvidos; 4) seu surgimento e evolução também variam. Porém, um dado animador neste cenário complexo é a sua permeabilidade à aprendizagem, e conseqüentemente, à intervenção.

A despeito destas dificuldades, algumas hipóteses podem ser levantadas a partir do que foi examinado acima: 1) é provável que se encontre diferença nesta tendência de resolução de conflitos, ligada a gênero, dado que as pesquisas constatam que a agressividade é mais comum entre meninos do que entre meninas; 2) é também provável, que em função da evolução ordenada, independente do tipo e da trajetória, sejam encontrados índices mais baixos deste tipo de tendência nas faixas etárias anteriores aos 10 anos; 3) é razoável esperar que as tendências agressivas decaiam a partir dos 10 anos, após ter atingido ali o seu ápice, pela incorporação de atitudes e valores contrários à violência que passarão a regular a conduta.

$\mathrm{Na}$ seção a seguir, serão analisados os comportamentos alternativos à agressividade, ou seja, não violentos, na resolução de problemas do tipo conflito interpessoal.

\section{Condutas não Agressivas e Resolução de Conflitos Interpessoais}

Como já observado, verifica-se, na revisão da literatura, maior atenção ao comportamento agressivo por parte das pesquisas, do que as formas alternativas e não violentas de resolução de conflitos interpessoais: a submissão e a assertividade. Esta última foi bastante estudada em pesquisas clínicas na década de 1970, sendo atualmente pesquisada como um dos componentes das denominadas habilidades sociais, o que ocorre pouco em nosso meio (Del Prette \& Del Prette, 1996). Nesta seção serão analisados, então, em que aspectos estes comportamentos diferenciam-se do agressivo: forma de manifestação e percepção do outro.

O comportamento assertivo caracteriza-se, como o agressivo, pelo enfrentamento da situação de conflito, evidenciado em comportamentos explícitos de defesa dos próprios direitos e opiniões, sem, porém, apelar para qualquer forma de coerção, como violência ou desrespeito ao direito e opinião alheios (Deluty, 1981). Além disso, envolve também expressão de pensamentos e sentimentos positivos, como, por exemplo, elogiar e concordar com opiniões dos outros. Neste sentido, é o mais desejável dos comportamentos em situações de conflito, embora nem sempre seja o mais aconselhável, como, por exemplo, em uma situação que envolve risco físico, ou quando ceder pode representar o fortalecimento de um vínculo.

Já o comportamento submisso envolve, como o assertivo, a consideração dos direitos e sentimentos dos outros, só que em detrimento dos próprios. Caracteriza-se, assim, pelo não enfrentamento de uma situação, por meio de fuga ou esquiva da mesma. É muitas vezes acompanhado pela negação da ocorrência de um conflito, valendo-se de argumentos defensivos como percepção de ausência de dano, de ameaça à auto-estima, etc. O comportamento submisso é mais freqüente que o assertivo, por ser visto, erroneamente, como mais adaptativo, ou desejável socialmente, por não envolver confronto (Del Prette \& Del Prette, 2002). Deve ser lembrado, porém, que o aspecto de não enfrentamento 
da situação nem sempre é motivado pelo que é considerado socialmente desejável. Muitas vezes, o comportamento submisso é motivado, simplesmente, pelo medo do confronto, constituindo, assim, o verso da agressividade (Deluty, 1979). Em outras palavras, muitos indivíduos se comportariam de modo agressivo em muitas situações, caso sentissem condições de obter sucesso com isso. É interessante observar a este respeito, que desde cedo, aos 5 anos em média, crianças são capazes de detectar o poder inibidor do sentimento de medo, pois crianças agressivas são percebidas por seus pares não só como agressivas, mas também como mais medrosas do que outras (Morais \& cols., 2001).

Supunha-se, inicialmente, que, tanto os comportamentos agressivos como os submissos, seriam mais freqüentes do que os assertivos, pela inabilidade de muitas crianças em avaliar a inadequação de um comportamento naquela situação (Deluty, 1981). Porém, as pesquisas têm revelado que crianças agressivas e submissas sabem que seus comportamentos são inadequados na resolução de conflitos interpessoais, mas têm dificuldade em considerar respostas não agressivas ou não submissas para resolver este tipo de problema, como se as soluções possíveis se resumissem a luta ou fuga, sem outras alternativas entre os dois extremos. Além disso, verificou-se que, mesmo quando são capazes de pensar nestas alternativas, algumas acham que se beneficiarão mais apresentando um comportamento agressivo ou submisso (Deluty,1995).

\section{A Importância da Cultura}

Os pais e outros responsáveis pelo cuidado da criança têm um papel importante sobre a escolha de resposta à situação de conflito. Os meninos gozam de maior liberdade para expressar agressividade, enquanto as meninas, geralmente, sofrem retirada de aprovação quando agem de modo não submisso. $\mathrm{O}$ estilo familiar de resolução de conflitos tem papel importante, pois, como em muitas outras situações, os pais atuam como modelos para as crianças (Deluty, 1981). Entretanto, tais diferenças na socialização não se resumem ao estilo familiar de resolução de conflitos, nem ao que é visto no seio da família como mais apropriado para um dado gênero. Pesquisas realizadas, segundo a orientação intercultural, têm demonstrado que as práticas de socialização variam de acordo com o funcionamento psicológico valorizado por uma dada cultura. Culturas como a norte americana, por exemplo, que enfatizam um funcionamento psicológico independente, tendem a socializar a criança em direção à autonomia, ao sentimento de eficácia, à expressão e defesa de seus desejos, direitos e sentimentos (Raeff, 1997), que poderiam, a nosso ver, levar a uma maior valorização da assertividade na interação social. Já culturas latinas, orientais e árabes tenderiam a socializar a criança para um funcionamento psicológico mais interdependente (Kitayama, 2001; Markus \& Kitayama, 1991), de valorização da convivência harmoniosa com o outro, de relacionamento e solidariedade (Dias, Vikan \& Gravas, 2000), o que resultaria em maior ênfase na observância de princípios morais, na obediência, no respeito à autoridade, etc. (Wang \& Leichtman, 2000), que poderiam, a nosso ver, favorecer maior submissão, ou pelo menos, uma percepção da submissão como algo socialmente desejável.

Além disso, professores e outros profissionais tendem a valorizar mais a obediência, a cooperação e outros comportamentos pró-sociais, possivelmente levando algumas crianças a concluir que quaisquer outras soluções para conflitos são indesejáveis (Del Prette \& Del Prette, 2002). Evidências desta tendência foram observadas em crianças de 5 anos em média, que interpretaram como cooperativos comportamentos explicitamente qualificados por um adulto como indicativos de submissão (Morais \& cols., 2001). É importante, neste sentido, lembrar o já apontado por Deluty (1995), o comportamento assertivo muitas vezes precisa ser ensinado, tanto no conteúdo como na forma: a expressão de pensamentos e sentimentos perde força se não for feita em um tom de voz firme e contato visual com o interlocutor.

Concluindo, os conflitos interpessoais podem ser resolvidos basicamente de três formas: por comportamentos coercitivos, como o agressivo, que fazem valer o direito ou opinião de quem os emite, mas sem consideração pelos direitos, sentimentos e opiniões do outro. Por outro lado, o comportamento submisso, o verso do agressivo, toma em consideração os direitos e sentimentos do outro, sem, porém, considerar os próprios, levando quem o emite a não reagir ou esquivar-se da situação. Finalmente, o comportamento assertivo, o mais desejável, e, por que não dizer, mais evoluído pelas coordenações cognitivo-afetivas que demanda, toma em consideração os próprios direitos, sentimentos e idéias, e os explicita, sem com isso ferir os alheios. Tais tendências de resolução de conflitos são, provavelmente aprendidas com modelos, como pais e professores, que aparentemente, ou agem como modelos de solução de problemas deste tipo, ou mesmo, estimulam involuntariamente comportamentos mais submissos, mais facilmente associáveis a comportamentos pró-sociais por eles valorizados. A cultura em que se processa a socialização da criança desempenha um papel fundamental neste aprendizado da resolução de problemas interpessoais, no sentido em que diferentes sistemas de valores expressam diferentes ideais de vida, que constituem o universo simbólico que dá significado às interações sociais de um dado grupo. Entretanto, tais sistemas de valores não devem ser considerados determinísticos, no sentido em que o indivíduo reflete necessariamente a cultura em que é socializado 
(Oyama, 1994; Raeff, 1997). Nem a cultura é simplesmente o reflexo de funcionamentos individuais agrupados. Pelo contrário, os indivíduos envolvem-se ativamente na interpretação do significado da experiência, e também, criam coletivamente mundos intencionais, que são mais que uma somatória de contribuições individuais. Os significados culturais são negociados na interação social, o que, além de abrir espaço para as diferenças individuais, imprime dinamismo à própria cultura que se modifica em função destas.

A partir do que foi concluído acima, é possível levantar algumas hipóteses: 1) como na tendência à agressão, serão encontradas diferenças nas demais tendências ligadas a gênero, esperando-se que meninas mostrem-se mais submissas e assertivas que meninos, pois são estimuladas a um comportamento não agressivo; 2) é provável que indivíduos com tendências agressivas apresentem, também, índices elevados da tendência complementar, a submissão, tendo em vista que o medo, ou, ainda, a percepção da desejabilidade social, é que tendem a guiar a conduta, mais que a consideração da importância da defesa dos próprios direitos e sentimentos e, também dos alheios; 3) tendo em vista que diferenças culturais expressam-se em sistemas de valores diferentes, possivelmente serão encontradas variações na manifestação das três tendências em ambientes culturais diversos.

\section{Método}

Conforme já explicado na apresentação do trabalho, foram realizados dois estudos com alunos de escolas públicas e privadas, sendo a diferença entre os mesmos o material utilizado: no Estudo 1, a Escala CATS foi aplicada em sua versão completa, em 13 situações acompanhadas das respectivas alternativas (Deluty, 1979). No Estudo 2, a escala foi aplicada na forma abreviada por Deluty (1981) em 10 situações, sem as alternativas, caracterizando um questionário aberto. Passaremos então à descrição de cada estudo e seus respectivos resultados, que serão discutidos e comparados na seção final.

\section{Estudo 1}

\section{Participantes}

Responderam à Escala CATS um total de 779 alunos, sendo 445 de uma escola privada da cidade de São Paulo e 334 de duas escolas públicas, uma na cidade de São Paulo e a outra na cidade de Campinas.Deste total, 386 eram do sexo feminino e 396 do sexo masculino. Na escola privada participaram 107 alunos de $2^{\mathrm{a}}$ série, 103 de $3^{\mathrm{a}}, 112$ de $4^{\mathrm{a}}$ quarta e 100 de $5^{\text {a }}$. Nas escolas públicas participaram 127 alunos de $5^{a}$ série, 97 de $6^{a}$ e 30 de $7^{a}$ série. Nas escolas públicas, a idade variou entre 12 e 16 anos ( $m=13,1$ anos). Na escola privada, a idade dos alunos variou entre 8 e 12 anos $(m=9,9$ anos). Nas duas escolas públicas, a direção desaconselhou a aplicação da pesquisa nas séries inferiores às pesquisadas, por considerar que os alunos teriam dificuldade em responder ao material na forma desenvolvida pelo autor.

\section{Material}

A Escala CATS foi-nos cedida por seu autor, Robert Deluty, que a desenvolveu em sua tese de doutorado (Deluty, 1979). Foi traduzida para o português por um psicólogo fluente em língua inglesa e esta tradução foi lida e avaliada por outro psicólogo, também fluente em língua inglesa. Não foi possível seguir o procedimento de traduzir e re-traduzir para a língua original, em virtude da necessidade de adaptações na tradução, como o gênero dos envolvidos no conflito, deixado deliberadamente indefinido por Deluty. Neste sentido, procedeu-se a um pré-teste de duas traduções com 99 alunos de $2^{\mathrm{a}}$ a $5^{\mathrm{a}}$ série de uma escola privada, aos quais foram fornecidas quatro versões do material. Em duas versões, a pessoa envolvida era do mesmo sexo do participante, feminino ou masculino, e nas duas outras, do sexo oposto. Embora não tenham sido verificadas diferenças nos escores médios obtidos, entrevistas com 10 alunos revelaram que, caso fosse necessária a especificação de gênero, seria melhor que fosse o mesmo da participante da pesquisa.

A Escala CATS, em sua versão completa, contém 13 descrições breves de situações de conflito interpessoal, acompanhadas de três tipos de resolução, uma agressiva, uma submissa e uma assertiva, contrapostas duas a duas, por três vezes, de tal modo que o participante deve escolher, três vezes, entre duas alternativas, aquela que lhe parece a mais típica das suas reações. Assim, são obtidos três escores de tendências de resolução de conflitos, um de agressividade, um de submissão e um de assertividade para cada situação. A escala foi apresentada impressa, em um folheto de três páginas, devendo o participante assinalar por escrito a sua opção em cada alternativa escolhida. No Anexo A é fornecido um exemplo de situação usada na escala.

As situações descritas na escala abordam os seguintes conflitos: sofrer provocações de colegas ou pais; sofrer injustiça de pais ou colegas; sofrer sanções dos pais, e sofrer humilhação pública infligida por colegas. As provocações entre colegas, as mais freqüentes, abrangem as seguintes situações: ser empurrado fora da fila da cantina; ser acusado de mesquinho por não emprestar a lição para ser copiada; ter um pedido de partilha de um doce recusado; ser criticado como menos inteligente, ou incompetente para participar de um jogo. Provocação por parte dos pais consiste em exposição a uma situação que provoca desconforto, do qual os pais 
estão cientes. Sofrer injustiça por parte de colegas envolve ter o livro preferido devolvido danificado, e, por parte dos pais, ser castigado pelo delito alheio. Sofrer os azares da sorte que provocam frustração consiste em perder um prêmio por um ponto e levar uma bolada na cabeça dada por uma criança pequena. Sofrer sanções dos pais envolve cumprir o horário de dormir no meio de um programa de TV e sofrer reclamações por estar fazendo muito barulho. Finalmente, a humilhação pública consiste em ser vaiado e xingado publicamente pelos colegas pelo mau desempenho em um jogo. Vale lembrar que muitas destas situações estão presentes no material utilizado por Dias e colaboradores (2000) para avaliar como crianças lidam com sentimentos de raiva e tristeza.

\section{Procedimento}

Em todas as escolas que participaram do estudo foi feito um contato inicial, apresentado-se os objetivos da pesquisa, o material a ser utilizado no caso (Escala CATS- versão completa), e as condições de aplicação. As escolas se encarregaram de informar aos pais sobre a realização da pesquisa e obter seu consentimento na reunião de entrega de notas.

A aplicação da escala foi realizada coletivamente em sala de aula por duas pesquisadoras do sexo feminino: uma, que atuando como aplicadora, explicava os objetivos da pesquisa, como o material deveria ser respondido, lendo em vOZ alta para a classe a primeira situação e suas alternativas, esclarecendo eventuais dúvidas. Vale observar que nas séries iniciais, $2^{\mathrm{a}}$ e $3^{\mathrm{a}}$, a escala e suas alternativas foram lidas na íntegra pela aplicadora, para auxiliar a compreensão das crianças sobre o preenchimento da mesma. A aplicadora foi acompanhada por uma observadora que ajudava no esclarecimento de dúvidas e na conferência do material. Em todas as salas foi, ainda, informado que a participação na pesquisa não era obrigatória, nem a identificação do participante, bastando as iniciais de seu nome e a sua idade. Foi também solicitado às professoras que se retirassem da sala de aula, de modo a garantir privacidade aos alunos.

\section{Resultados}

Serão analisadas, em primeiro lugar, as tendências predominantes de resolução de conflitos na amostra brasileira, comparando-se ao que foi encontrado na amostra americana estudada por Deluty (1979), de modo a verificar o seu grau de aplicabilidade em nosso meio. Para tanto, foram comparadas as médias encontradas em cada amostra, de acordo com a sua distribuição nas três tendências de resolução de conflitos. Observou-se que, de modo geral, as duas amostras mostram-se bastante semelhantes, no sentido de que as tendências de resolução de conflitos predominantes são as mesmas. Em outras palavras, tanto alunos brasileiros como americanos escolheram prioritariamente a resolução de conflitos de tipo assertivo, seguida pela de tipo submisso, e por último, as agressivas. Porém, foram encontradas diferenças pequenas, mas significativas, nas médias de assertividade e submissão, sendo a média de tendência à submissão dos participantes da amostra brasileira significantemente maior $(t=2,40 ; p<0,01)$ e a de assertividade significantemente menor $(t=1,955 ; p<0,05)$ que as da amostra americana.

Este mesmo padrão de tendências de resolução de conflitos é mantido quando se analisa a distribuição das médias das três tendências segundo o gênero nas duas amostras, pois as médias de agressividade de meninos e meninas brasileiros e americanos não se diferenciam significantemente, mantendo-se, ainda, como a menor tendência de resolução de conflitos. Já as médias relativas à tendência à submissão, a intermediária nas duas amostras, de meninas e meninos brasileiros, são significantemente mais elevadas que as de ambos os gêneros na amostra americana (respectivamente, $t=2,006 ; \quad p<0,05 ; \quad t=1,58 ; \quad p<0,05$ ), confirmando, assim, o já verificado anteriormente nas amostras como um todo. No entanto, com relação à diferença relativa à assertividade, já constatada anteriormente entre as duas amostras, verifica-se que o gênero é uma variável importante, pois só as meninas brasileiras diferenciam-se como menos assertivas que as americanas $(t=-2,8 ; p<0,01)$, não se encontrando diferença quanto a esta tendência entre meninos americanos e brasileiros.

Analisando estas tendências por tipo de escola, encontramos novamente ausência de diferença nas médias da tendência à agressividade, ainda a menos escolhida, entre alunos brasileiros e americanos nos dois tipos de escola, pública e privada. Também não se encontram diferenças nas médias das tendências à assertividade e submissão entre alunos de escola privada dos dois países. Diferenças pequenas, mas significativas, são encontradas entre alunos de escola pública, americanos e brasileiros, nas médias das tendências predominantes, assertividade e submissão, sendo as médias de submissão dos alunos brasileiros de escola pública significantemente maiores $(t=4,55 ; p<0,01)$ e as de assertividade menores $(t=-3,76 ; p<0,01)$ que as de alunos de escola pública americanos. Quando se analisam as tendências por série, verifica-se que as médias da tendência à agressividade e à submissão de alunos americanos de sexta série são significativamente maiores $(t=2,22 ; p<0,05$ e $t=2,14$; $p<0,05)$ que as dos brasileiros do mesmo nível de escolaridade. Encontram-se ainda diferenças significativas entre as médias de alunos de $3^{\mathrm{a}}, 4^{\mathrm{a}}$ e $5^{\mathrm{a}}$ série na tendência à assertividade, pois as médias de assertividade de alunos 
brasileiros de $3^{\text {a }}$ série são significantemente maiores $(t=$ 2,19; $p<0,05)$ que as médias de alunos da mesma série americanos, o que muda na $4^{a}$ e $5^{a}$ série, em que as médias de assertividade de alunos brasileiros passam a ser significantemente menores $(t=-2,64 ; p<0,01)$.

Resumindo os resultados relativos à comparação das duas amostras, verificamos a existência de semelhanças na tendência geral de resolução de conflitos, na medida em que soluções assertivas de conflito interpessoal são preponderantes nas duas amostras e as agressivas as mais raras, verificando-se, portanto, que o instrumento mostrase, de modo geral, adequado para aplicação em nosso meio. Deve ser lembrado, porém, que quando esta análise é refinada no sentido de comparar a incidência de cada tendência nas duas amostras, ou mesmo, em sub-amostras, compostas por gênero e tipo de escola, verifica-se que a resolução por submissão é mais acentuada na amostra brasileira que na americana e a assertiva nesta última, diferenças que manifestam-se, principalmente, entre meninas, alunas de escola pública, de séries mais avançadas.

Analisaremos, a seguir, como se apresentam estas tendências na amostra brasileira, de modo a obter uma descrição mais pormenorizada das mesmas em nosso meio. $\mathrm{Na}$ tendência à assertividade, a análise de variância mostrou que a tendência assertiva de resolução de conflitos é mais preponderante no sexo feminino que no masculino $(F(11,767)=18,16 ; p<0,00)$. Também foram observadas diferenças em relação à série, $(F(11,767)=2,67 ; p<0,05)$. O teste LSD revelou que entre alunos de $5^{\mathrm{a}}$ a $7^{\mathrm{a}}$ série, encontrase menor tendência à resolução de conflitos por assertividade do que entre alunos de $2^{a}$ e $3^{a}$ série, indicando uma progressiva diminuição desta com o progresso na escolaridade, independente do gênero e do tipo de escola, restrita no caso, à $5^{\text {a }}$ série.

No que diz respeito à tendência à agressividade, a ANOVA evidenciou que o gênero é uma variável importante, pois as meninas mostraram-se significativamente menos agressivas que os meninos $(F(11,767)=80,894 ; p<0,00)$. Não foram encontradas diferenças significativas entre as séries, nem interação entre as variáveis gênero e nível de escolaridade.

Ainda examinando a variação das tendências de resolução de conflito segundo o gênero, a ANOVA realizada revelou maior submissão entre as meninas $(F(11,767)=6,242 ; p<0,00)$ do que entre meninos, havendo, entretanto, interação entre gênero e série, pois esta diferença diminui significativamente na $6^{a}$ e $7^{a}$ séries, o mesmo ocorrendo entre os meninos, que aumentam em submissão, na medida em que progridem na escolaridade. Em outras palavras, meninas e meninos tendem a se tornar mais semelhantes na tendência à submissão, na medida em que progridem na escolaridade.
Analisadas as tendências por tipo de escola freqüentada, o teste $T$ revelou que as resoluções de conflitos agressiva $(t(777)=-1,963 ; p<0,05)$ e assertiva $(t(777)=-3,719 ; p<0,05)$ são mais freqüentes entre alunos de escola privada do que entre alunos de escola pública; que se mostram mais submissos (t(777) 6,$242 ; p<0,0)$ que os primeiros.

Finalmente, analisando os tipos de situação em que foram escolhidas soluções diferentes da assertiva, a preponderante, como mostrado acima, encontra-se maior tendência à submissão nas situações de ser criticado como menos inteligente por um colega e ter um pedido recusado por um colega. Maior tendência à agressividade foi encontrada na situação de sofrer repreensão dos pais pelo barulho.

Resumindo os resultados encontrados, verificamos que a amostra brasileira assemelha-se, como um todo, à americana pela predominância de dois tipos de resolução de conflitos, assertivo e submisso. Porém, quando se comparam as médias de cada tendência nas duas amostras, verifica-se que americanos são um pouco mais assertivos que brasileiros sendo estes, por sua vez, mais submissos que americanos. Ao que tudo indica, esta diferença é mais presente entre alunos de escola pública, do sexo feminino, de séries mais avançadas. $\mathrm{Na}$ amostra brasileira verificam-se diferenças entre os gêneros quanto à incidência de cada tendência, sendo meninos mais propensos à escolha de soluções de conflito agressivo e meninas ao assertivo. Os meninos tornam-se progressivamente mais submissos e menos agressivos com o avanço na escolaridade, enquanto as meninas manifestam maior estabilidade em suas tendências. Alunos de escola pública mostram tendência à maior submissão, enquanto alunos de escola privada a maior agressividade e assertividade.

Considerando as diferenças encontradas entre a amostra brasileira e americana, e ainda, entre os dois tipos de escola, cuja comparação ficou restrita à $5^{a}$ série, pareceu-nos pertinente verificar, em maior detalhe, a evolução das tendências verificadas em séries mais avançadas na escola privada. Além disso, a presença de alternativas pode induzir respostas que não ocorreriam caso estas estivessem ausentes (Schwarz, 1999). Neste sentido, o Estudo 2 procurou verificar a evolução das tendências encontradas em séries mais avançadas na escola privada, e, também, se estas se mantém na ausência de alternativas.

\section{Participantes}

\section{Estudo 2}

Participaram do Estudo 2, 320 alunos, sendo 110 de escola pública e 210 de escola privada, sendo 174 meninas e 146 meninos. Destes, 104 freqüentavam a $5^{\mathrm{a}}$ série, 109 a $6^{\mathrm{a}}$ série e 107 a $7^{a}$ série. A idade média na escola privada era de 12,04 anos e 12,7 anos na pública. 


\section{Material}

A Escala CATS contendo dez situações de conflito interpessoal, conforme já realizado por Deluty (1981), foi aplicada sem as alternativas, impressa em um folheto de duas páginas. As situações retiradas por sugestão de Deluty foram duas envolvendo conflito com os pais, a da exposição à situação que causa desconforto e a da reclamação por excesso de barulho; e a terceira, aquela em que se é acusado de mesquinharia pelo colega a quem se negou o empréstimo da lição.

\section{Procedimento}

As condições de aplicação do estudo 2 foram basicamente as mesmas seguidas no Estudo 1. Após o contato inicial com as escolas e informação aos pais como no Estudo 1, foi feita a aplicação coletivamente em sala de aula, estando presentes duas aplicadoras do sexo feminino, sem a presença da professora. Os procedimentos de explicação dos objetivos do estudo, ausência de obrigatoriedade na participação e identificação, foram explicados como no Estudo 1, assim como responder às questões, esclarecendo-se eventuais dúvidas. Cerca de um quarto dos alunos de $5^{\mathrm{a}}$ série da escola pública recusou-se a participar, por considerar muito trabalhosa a resposta escrita ao questionário.

Finalmente, a categorização das respostas em submissas, assertivas e agressivas foi realizada de modo independente por dois juízes, que obtiveram um índice de concordância de $93 \%$ entre si, segundo a fórmula padrão de soma das concordâncias e discordâncias divididas pelo número de concordâncias multiplicadas por 100. As discordâncias encontradas foram resolvidas após discussão dos critérios envolvidos no julgamento. É importante ressaltar que foram encontradas respostas que combinavam duas tendências, pois continham elementos de ambas ao mesmo tempo, que foram categorizadas como mistas. Um exemplo deste tipo de resposta, dada por uma menina na situação do que faria se levasse uma bolada de uma criança menor: Depende: Nada, se foi sem querer. Se foi por querer, chutava a bola longe. Contrastando com esta mistura de submissão e agressividade, teríamos como resposta típica, categorizada como assertiva para a mesma situação: Falaria para tomar mais cuidado.

\section{Resultados}

A aplicação da Escala CATS sem as alternativas revelou os seguintes aspectos: as tendências predominantes de resolução de conflitos foram: submissão, agressividade, mistas de submissão e agressividade, e, por último assertividade. Em outras palavras, quando solicitados a recuperar da memória como reagiriam em um conflito interpessoal, os alunos forneceram prioritariamente soluções de tipo submisso
( $M=111)$, agressivo $(M=91,9)$, ou uma mistura combinando os dois tipos de solução $(M=52,1)$. As respostas assertivas $(M=49,5)$ ficaram abaixo destas últimas. Foram encontradas outras tendências mistas, combinando soluções assertivas e submissas $(M=10,2)$ ou soluções agressivas e assertivas $(M=7,7)$

Quando analisadas segundo o gênero, verificou-se a manutenção parcial das mesmas tendências verificadas para a amostra como um todo: submissão e agressividade como as duas primeiras tendências de resolução. Já na terceira tendência, verifica-se uma diferença importante: os meninos forneceram proporcionalmente mais soluções mistas, combinando elementos de submissão e agressividade e as meninas mais soluções assertivas. Além disso, os escores médios revelam que meninos fornecem um pouco mais soluções julgadas agressivas $(M=47)$ que meninas $(M=45)$, enquanto essas últimas apresentam mais soluções submissas do que eles $(M=60$ para $M=50)$.

Comparando-se estas tendências de resolução de conflitos por tipo de escola, verificamos a manutenção das duas primeiras, isto é, as soluções submissas são proporcionalmente as mais freqüentes, tanto na escola pública $(39 \%)$ como na privada (33\%) e, logo a seguir, as soluções agressivas (pública $=32 \%$ e privada $=28 \%$ ). Além disso, nos dois tipos de escola, soluções mistas, que combinam ao mesmo tempo elementos de solução de submissão e agressividade são mais apontadas que soluções assertivas (privada $=19 \%$ e pública $=14 \%$ ). Os alunos de escola privada apontam, proporcionalmente, um pouco mais soluções julgadas assertivas (17\%) que os de escola pública $(13 \%)$, e, proporcionalmente menos de tipo agressivo ou submisso. Por outro lado, as soluções mistas, que combinam as duas tendências, são proporcionalmente mais freqüentes na escola privada que na pública.

Finalmente, quando se examinam estas tendências nas três séries, não se observam diferenças acentuadas em relação ao que já havia sido verificado anteriormente: as três tendências de solução são escolhidas na mesma ordem, isto é, submissas, agressivas e assertivas, com a exceção da sétima série, que aponta maior proporção de soluções julgadas mistas, por combinarem elementos de agressão e submissão do que soluções assertivas.

Com relação às situações que provocam mais um tipo de solução do que as outras, verificamos que conflitos com colegas favorecem mais soluções do tipo submisso, tanto entre meninas como entre meninos, independente do tipo de escola, que as demais situações, destacando-se entre estas: humilhação pública infligida por colegas, recusa de colegas a pedido para participar de um jogo, recusa de colega ao pedido de um doce, crítica de um colega sobre a inteligência do participante e perda de um prêmio para um colega por 
diferença de apenas um ponto. Também foram encontradas soluções generalizadas, no caso de agressividade, a situação de sofrer punição injusta por parte dos pais e ser empurrado fora da fila por um colega. Já as situações do livro preferido ser devolvido danificado por um amigo, levar uma bolada na cabeça dada por uma criança menor, e ser obrigado a cumprir o horário de dormir pelos pais, no meio de um programa de TV, sofreram influência do gênero: na situação do livro danificado pelo amigo, as meninas mostraram-se proporcionalmente mais assertivas $(38,4 \%$ ) que os meninos (7\%), que se mostraram mais agressivos (52\%); na situação da bola lançada na cabeça por uma criança pequena, as meninas mostraram maior tendência à submissão $(36 \%)$ que os meninos, que mostraram igualmente as duas tendências, submissão $(31,9 \%)$ e agressividade $(31,9 \%)$, e finalmente, na situação em que os pais interrompem o programa de TV, os meninos mostraram-se proporcionalmente mais agressivos $(38,7 \%)$ e as meninas mais assertivas $(31,8 \%)$. Tais diferenças confirmam o que já havia sido verificado anteriormente nas tendências de cada gênero independente da situação.

Em suma, quando solicitados a fornecer soluções resgatadas da memória para os mesmos problemas do Estudo 1, os participantes manifestaram duas tendências: submissão e agressividade, independente do gênero, idade e tipo de escola. Variações foram encontradas na terceira e, menos resgatada tendência: a assertividade mais comum entre alunas de escola privada, e soluções combinando elementos de submissão e agressividade, mais freqüentes entre alunos do sexo masculino, de $7^{a}$ série de escola pública. Assim, o Estudo 2 favorece a conclusão de que o resgate da memória de soluções para problemas interpessoais evidencia tendências muito mais de tipo submisso e agressivo em nosso meio, pois só foram encontradas diferenças com relação à terceira e última tendência, que variou entre assertividade e uma mistura de elementos de submissão e agressividade. Neste sentido, acentua-se o que já havia sido vislumbrado no Estudo 1, a evolução, em nosso meio, para a resolução de conflitos mais de tipo submisso, seguida de sua contrapartida menos desejável, a agressão.

\section{Discussão}

Retomaremos, em primeiro lugar, os resultados dos dois estudos, confrontando-os com as hipóteses levantadas a partir da literatura, passando em seguida às conclusões:

No Estudo 1, verificamos semelhança global entre as amostras brasileira e americana, pela predominância dos mesmos tipos de resolução de conflitos, assertivo, submisso e agressivo, em último lugar. Porém, quando se comparam as médias de cada tendência nas duas amostras, verifica-se que americanos são um pouco mais assertivos que brasileiros, sendo estes, por sua vez, mais submissos que americanos. Ao que tudo indica, esta diferença é mais acentuada entre alunos de escola pública, do sexo feminino, de séries mais avançadas. A este respeito, vale lembrar que se confirma a hipótese de especificidades culturais na resolução de conflitos interpessoais levantada a partir do exame da literatura, e que podem explicar, pelo menos em parte, as diferenças encontradas. A ênfase no funcionamento psicológico independente, dada pela cultura norte-americana, de autonomia na expressão e defesa dos próprios direitos e sentimentos, parece confirmada nas diferenças encontradas nas médias de maior assertividade e menor submissão. Já a ênfase de culturas da interdependência, latinas, africanas e orientais como a nossa, no socializar a criança para um funcionamento psicológico mais ajustado ao outro, à obediência e respeito à autoridade, também se confirma na maior tendência à submissão encontrada nesta pesquisa. Neste sentido, tais resultados de maior submissão e menor assertividade entre brasileiros, assim como a maior assertividade entre norte americanos, apontam para diferenças culturais já constatadas em contextos de pesquisa semelhantes (Dias \& cols., 2000).

Foram verificadas ainda na amostra brasileira, diferenças atribuíveis ao gênero, quanto à incidência de cada tendência, sendo meninos mais propensos à escolha de soluções de conflito agressivo e meninas ao assertivo. Os meninos tornam-se progressivamente mais submissos com o avanço na escolaridade, enquanto as meninas mostram maior estabilidade em suas tendências, o que confirma as hipóteses levantadas com base na literatura sobre diferenças de gênero e idade. Alunos de escola pública mostram tendência à maior submissão, enquanto alunos de escola privada a maior agressividade e assertividade, o que não poderia ser previsto em virtude da ausência de dados a este respeito na literatura consultada.

Já o Estudo 2 evidenciou que a amostra estudada revelou tendências predominantemente submissas e agressivas na resolução baseada no resgate da memória dos mesmos conflitos. Encontraram-se diferenças, apenas com relação à predominância da terceira e menos apontada tendência: assertividade, mais comum entre meninas, alunas de escola privada e soluções mistas, mais freqüentes entre alunos do sexo masculino de escola privada da $7^{a}$ série. Os alunos de escola pública mostraram-se mais submissos e agressivos do que os de escola privada.

Em suma, as soluções resgatadas da memória para conflitos interpessoais diferem daquelas dadas na presença de alternativas, como as pesquisas comparando instrumentos já vem apontando há algum tempo (Schwarz, 1999). Porém, deve ser lembrado que esta diferença refere-se somente à maior ou menor predominância dos mesmos três tipos 
identificados por Deluty (1979), que se mostraram, ainda, quando resgatadas da memória, muito semelhantes ao proposto nas alternativas da escala desenvolvida pelo autor. Além disso, encontrou-se alguma coincidência de situações que provocaram nos dois estudos o mesmo tipo de solução, no caso a de tipo submissa: as situações de crítica à inteligência e a recusa a um pedido. A este respeito, deve ser lembrado ainda, que situações muito semelhantes foram identificadas como relevantes para a investigação em nosso meio de como crianças lidam com sentimentos (Dias \& cols., 2000), e, também, habilidades sociais (Del Prette \& Del Prette, 2002).

Neste sentido, verifica-se que alunos brasileiros são sensíveis, desde muito cedo, ao que é considerado socialmente desejável na resolução de conflitos interpessoais, pois verificamos predominância de soluções assertivas também nas séries iniciais, como a $2^{\mathrm{a}}$ e $3^{\mathrm{a}}$ série no Estudo 1 . Porém, quando solicitados a recuperar, da memória, o tipo de resolução que dariam à situação descrita no instrumento, verifica-se que as soluções submissas e agressivas são mais freqüentes, confirmando a dificuldade, já apontada por Deluty (1981), em encontrar soluções alternativas para conflitos. Convém, entretanto, lembrar que não foi possível contar com a participação de alunos mais jovens no Estudo 2, mais assertivos que os mais velhos no primeiro estudo, em função das características do instrumento, que encontrou resistência até entre alunos de $5^{a}$ série. Fica então em aberto a que variável atribuir a menor tendência à assertividade encontrada no Estudo 2, se ao fator idade, verificado no crescimento da submissão com o decorrer do desenvolvimento constatado no Estudo 1, ou aos esquemas de solução mais submissos presentes na memória, estimulados pela cultura, mais colocados em evidência pelas características do instrumento aberto. Além disso, o Estudo 1 evidenciou que não só a submissão vai aumentando com a idade, mas que isto ocorre, principalmente, entre alunos do sexo masculino, sendo o feminino mais estável e assertivo, o que foi confirmado no Estudo 2. Seria importante então construir instrumentos que permitissem o acesso à resposta espontânea do aluno das séries iniciais, garantindo, ao mesmo tempo, que a desejabilidade social fosse minimizada na situação. Contudo, não deve ser esquecido que a tendência progressiva à submissão, verificada entre meninos no Estudo 1, foi parcialmente encontrada também no Estudo 2, no qual meninos de $7^{a}$ série mostraram maior tendência a combinar submissão e agressividade em suas soluções aos problemas do que assertividade. As hipóteses de que a agressividade é mais comum entre meninos e diminui com a idade foram confirmadas de modo mais acentuado no Estudo 1.

Relacionado a este último aspecto, o que desperta a atenção na comparação dos resultados é a atenuação das diferenças de gênero, principalmente na tendência à agressividade, quando são solicitadas respostas que demandam a recuperação da memória de soluções para os conflitos interpessoais. Neste sentido, as meninas ainda mostram maior tendência à assertividade e submissão que os meninos, mostrando, porém, maior tendência à agressividade que a revelada no instrumento fechado, contendo alternativas. É provável que as maiores sanções sociais a que estão sujeitas, se manifestarem agressividade, as impeçam de manifestá-la (Deluty, 1981) quando são oferecidas outras alternativas, como as assertivas presentes na escala. Porém, em situações de menor controle social, em que é necessária a recuperação de soluções da memória, revelam-se preferencialmente mais agressivas que assertivas como no Estudo 1.

Um resultado não esperado, porém importante, foi a identificação de diferenças já evidenciadas no Estudo 1 entre os dois tipos de escola, pública e privada, que se mantiveram, mesmo que mais atenuadas no Estudo 2: os alunos de escola privada mostraram-se mais assertivos que os de escola pública, que foram mais submissos e agressivos nos escores e freqüências médios encontrados.

Finalmente, alguns resultados encontrados indicam algumas inter-relações da cognição e afetividade: a sensibilidade ao que é visto como mais adequado socialmente, como as resoluções de tipo assertivo, preponderantes nas duas amostras bem precocemente, o ajustamento ao que é apropriado para um dado gênero, como a menor agressividade das meninas, nas duas amostras e nos dois estudos mais submissas que os meninos, a trajetória em direção à conformidade social, no caso, da cultura brasileira, ao ajustamento ao outro, pela resolução por submissão preponderante que foi encontrada no Estudo 2.

Portanto, com relação à motivação inicial deste trabalho, de esclarecer alguns aspectos ligados à violência, as conclusões favorecidas são:

Instrumentos como a escala CATS favorecem a aplicação mais extensa de investigações do tipo survey, mas são menos potentes para aferir a influência mais sutil de variáveis como a desejabilidade social moldada pela cultura. Por outro lado, são úteis na medida em que apontam tendências como as identificadas nesta pesquisa: a) maior tendência à submissão e menor assertividade em nosso meio, como revelado nos dois estudos; b) a existência de uma trajetória em direção à conformidade social, pelo aumento na tendência à submissão com a idade, presente nos dois estudos, que era mesmo de se esperar a partir do encontrado na revisão teórica deste trabalho; c) um progressivo esvanecimento da diferença entre gêneros, na medida em que no decorrer desta trajetória, meninos tornam-se mais semelhantes a meninas; d) uma diferença importante entre os dois tipos de escola apontada 
nos dois estudos, pela maior presença de soluções submissas na escola pública do que na privada.

Relacionada a este aspecto, a necessidade de pesquisas que explorem alguns aspectos como a adaptação de instrumentos e procedimentos, a exemplo do desenvolvido por Del Prette e Del Prette (2002) para aferir habilidades sociais, que permitam o acesso a respostas a questões abertas por parte dos alunos mais jovens, sem com isso induzir respostas socialmente desejáveis, como por exemplo, as que poderiam ocorrer na presença do experimentador.

E por último, o que não implica em menor importância que os aspectos apontados acima, a necessidade de programas educacionais que busquem desde cedo levar as crianças, não só à percepção dos próprios sentimentos e direitos, mas, também dos alheios, aprendendo com isso a solucionar conflitos de modo pacífico, flexível e diversificado, conciliando direitos e sentimentos de todos os envolvidos. A constatação de que os esquemas de solução de problemas interpessoais recuperados pelos participantes deste estudo são predominantemente de tipo submisso e agressivo nos parece preocupante, tendo em vista que ambas representam os dois lados de uma mesma moeda.

\section{Referências}

Astor, R. (1994). Children's moral reasoning about family and peer violence: The role of provocation and retribution. Child Development, 65, 1054-1067.

Azevedo, M. A \& Guerra, V. (1995). Violencia doméstica na infância e na adolescência. São Paulo: Robe.

Borum, R. (2000). Assessing violence risk among youth. Journal of Clinical Psychology, 56, 1263-1288.

Briggs, H.; Tovar, D. \& Corcoran, K. (1996). The children's action tendency scale: Is it reliable and valid with latino youngsters? Research in Social Work Practice, 6, 229-235.

Cecconello, A. M. \& Koller, S.H. (2000). Competência social e empatia: Um estudo sobre resiliência com crianças em situação de pobreza. Estudos de Psicologia, 5, 71-93.

Del Prette, Z. A. P. \& Del Prette, A. (1996). Habilidades sociais: Uma área em desenvolvimento. Psicologia: Reflexão e Crítica, 9, 233-255.

Del Prette,Z. A.P.\&Del Prette, A. (2002). Avaliação de habilidades sociais de crianças com um inventário multimídia: Indicadores sociométricos associados a freqüência versus dificuldade. Psicologia em Estudo, 7, 61-73.

Deluty, R. H. (1979). The children's action tendency scale: A self report measure of aggressiveness, assertiveness and submissiveness in children. Journal of Consulting Psychology, 47, 1061-1071.

Deluty, R. H. (1981). Alternative thinking ability of aggressive, assertive, and submissive children. Cognitive Therapy and Research, 5, 309-312.
Deluty, R. H. (1995). Assertiveness vs aggressiveness: What's the difference? Maryland Family Magazine, August, 26-27.

Dias, M. G. B. B., Vikan, A. \& Gravas, S. (2000). Tentativa de crianças em lidar com as emoções de raiva e tristeza. Estudos de Psicologia, 5, 49-70.

Edmunds, G. \& Kendrick, C. (1980). The measurement of human aggressiveness. NY: Ellis Horwood.

Ellsworth, P. (1994). Sense, culture and sensibility. Em S. Kitayama \& E. Markus (Orgs.), Emotion and culture: Empirical studies of mutual influence (pp. 23-49).Washington, DC: American Psychological Association.

Geen, R. G.(1990). Human aggression. NY: Academic Press.

Kitayama, S. (2001). Culture psychology of the self: A renewed look at independence and interdependency. International Journal of Psychology, 35, 204-234.

Loeber, R \& Hay, D. F. (1997). Development of aggression. Anmual Review of Psychology, $48,411-447$.

Loeber, R. \& Stouthamer-Loeber, M. (1998). Development of juvenile aggression and violence. American Psychologist, 53, 242-259.

Magalhães, C. M. C. \& Otta, E. (1995). Agressão em crianças: Influências do sexo e de variáveis situacionais. Psicologia: Teoria e Pesquisa, 11,7-12.

Markus, H. R. \& Kitayama, S. (1991). Culture and the self: Implications for cognition, emotion and the self. Psychological Review, 98, 224-253.

Morais, M.L.S., Otta, E. \&Scala, C. T. (2001).Status sociométrico avaliação de características comportamentais: Um estudo de competências sociais em pré-escolares. Psicologia: Reflexão e Crítica, 14, 191-131.

Otta, E. \& Sousa, I.J.F. C. (1999). Crianças alfa e crianças ômega: Um estudo sobre papéis desempenhados num grupo de pré-escola. Em A. M. Carvalho (Org.), O mundo social da criança: Natureza e cultura em ação (pp. 33- 48). São Paulo: Casa do Psicólogo.

Oyama, S. (1994). Rethinking development. Em P. Beck (Org.), Psychological Anthropology (pp.185-196). Connecticut: Praeger.

Raeff, C. (1997). Individuals in relationships: Cultural values, children's social interactions, and the development of an american individualistic self. Developmental Reviem, 17, 205-238.

Sastre, G. \& Moreno, M. (2002). Resolução de conflitos e aprendizagem emocional: Gênero e transversalidade.São Paulo: Moderna.

Schwarz, N. (1999). Self-reports: How the questions shape the answers. American Psychologist, 54, 91-105.

Sternberg, R. (2000). Psicologia cognitiva (M. R. B. Osório, Trad.). Porto Alegre: Artes Médicas.(Original publicado em 1996)

Tremblay, R. E. (2000). The development of aggressive behavior during chidhood: What have we learned in the past century? International Journal of Behavioral Development, 24, 129-141.

Yunes, J. (2002). Prefácio. Em M. F. Westphal (Org.), Violencia e criança (pp.11-12). São Paulo: EDUSP.

Wang, Q. \& Leichtman, M. D. (2000). Same beginnings, different stories: A comparison of american and chinese children's narratives. Child Development, 71, 1329-1346.

Sobre a autora

Recebido: 27/5/2003

Última Revisão: $7 / 10 / 2003$

Aceite Final: 21/10/2003

Maria Isabel da Silva Leme é Psicóloga e Professora do Instituto de Psicologia da Universidade de São Paulo, onde leciona nos cursos de graduação e pós-graduação.Realiza pesquisas sobre as relações de interdependência entre cognição e afetividade na perspectiva da Psicologia Cultural. 


\section{Anexo A}

\section{Exemplo de uma situação da escala CATS:}

Você está jogando um jogo com seus amigos. Você tenta jogar o melhor possível, mas erra o tempo todo. Seus amigos começam a caçoar de você e xingam você de vários nomes. O que você faria?

a. Largaria o jogo e iria para casa.

b. Bateria em quem está caçoando mais.

Ou

a. Falaria para parar porque não iriam gostar se fosse com eles.

b. Largaria o jogo e iria para casa.

ou

a. Bateria em quem está caçoando mais.

ou

b.Falaria para parar porque não iriam gostar se fosse com eles. 